\title{
FORMAS ALTERNATIVAS DE PRODUÇÃO EM ASSENTAMENTOS DE REFORMA AGRÁRIA DO MST \\ Agroecologia em questão: O caso do assentamento Ander Rodolfo Henrique - Diamante D’Oeste - Paraná
}

André Luiz de Souza ${ }^{1}$

RESUMO: Este estudo tem por objetivo geral analisar os processos de ruptura e de descontinuidade das práticas agroecológicas em assentamento de reforma agrária do MST bem como analisar o condicionamento dos assentados no Projeto de Desenvolvimento do Assentamento (PDA) a ser colocado em prática. Neste sentido, analisamos a distância das representações objetivas e subjetivas dos assentados e dos organizadores em relação à agroecologia. Os procedimentos metodológicos adotados foram a aplicação de questionários e a realização de entrevistas com 46 famílias de assentados. Utilizou-se de farta bibliografia com o marco teórico da agroecologia e da questão agrária. Os primeiros resultados da pesquisa indicam que a proposta do PDA não foi bem aceita pelos assentados.

Palavras-chave: Assentamentos. Agroecologia. Desenvolvimento sustentável.

Resumen: Este estudio tiene por objetivo analizar los procesos de ruptura y de discontinuidad de las prácticas agroecológicas en un determinado asentamiento de reforma agraria del MST, así como el condicionamiento de los asentados en el Proyecto de Desarrollo del Asentamiento (PDA) a ser puesto en práctica. En ese sentido, analizamos la distancia de las representaciones objetivas y subjetivas de los asentados y de los organizadores con relación a la agroecología. Los procedimientos metodológicos adoptados fueron la aplicación de cuestionarios y la realización de entrevistas con 46 familias de asentados. Se utilizó abundante bibliografía con el marco teórico de la agroecología y de la cuestión agraria. Los primeros resultados de la investigación indican que la propuesta del PDA no fue bien aceptada por los asentados.

Palabras clave: Asentamientos. Agroecología. Acondicionamiento, Desarrollo sostenible.

\section{INTRODUÇÃO}

Esta pesquisa, que está sendo desenvolvida junto a um assentamento de famílias que desempenham atividades voltadas para a sustentabilidade, tem como delimitação do tema práticas agroecológicas em áreas de reforma agrária no assentamento rural Ander Rodolfo Henrique em Diamante D’Oeste, no estado do Paraná.

O estudo tem por objetivo geral analisar os processos de ruptura e de descontinuidade das práticas agroecológicas no assentamento e o condicionamento dos assentados no Projeto de Desenvolvimento Sustentável, assim como analisar a distância das representações dos assentados e dos organizadores e os diferentes sentidos da agroecologia para esses sujeitos.

No assentamento rural em estudo, há 108 famílias assentadas e distribuídas em uma área total de 3.097,69 hectares, o que constitui um avanço para a reforma agrária e para as lutas dos trabalhadores organizados do campo.

Trabalhar com áreas de assentamentos rurais de reforma agrária, demanda desafios para as Ciências Humanas e Sociais; principalmente após o surgimento de uma nova ótica de assentamentos, após os anos 2000. Nesta lógica, estes locais seriam voltados para sustentabilidade ambiental, econômica, social e cultural. A agroecologia como matriz de

\footnotetext{
${ }^{1}$ Professor de Sociologia e Psicologia, IFPR-Palmas, Mestre em Ciências Sociais, Especialista em Educação do Campo. Sociólogo nº000433/Pr.
} 
produção tecnológica seria a chave para romper com o paradigma de agricultura mercadológica possibilitando uma nova estruturação dos assentamentos rurais.

Neste sentido, faz-se necessária uma investigação aguçada para entender o processo de construção das práticas agroecológicas e posteriormente rompimento destas no assentamento Ander Rodolfo Henrique. Local protagonista, no estado Paraná, em implantar o Projeto de Desenvolvimento de Assentamento Sustentável. No entanto, esse projeto não teve sucesso na estruturação da matriz tecnologia agroecológica.

A demanda de se buscar novas formas de sustentabilidade ambiental sobrecarrega os assentados da Reforma Agrária, principalmente os movimentos sociais do campo, que têm o desafio de construir um novo paradigma para a agricultura sustentável. Neste estudo, buscase entender como estas práticas são desenvolvidas no decorrer dos espaços de assentamentos e como são geridas pelos sujeitos que estão no cotidiano do desenvolvimento destas novas concepções de agricultura. A construção deste novo paradigma de agricultura carrega consigo uma polissemia de sentido sobre o conceito de agroecologia. A agroecologia não pode ser aplicada como uma medida punitiva a esses sujeitos que estão na luta por um pedaço de chão para poder sobreviver e alicerçar raízes.

Conhecer a realidade destas famílias de agricultores-camponeses fundamental para o pesquisador, principalmente para interpretar os fatos ocorridos e vivenciados pelos sujeitos a serem pesquisados. Entender as relações entre as representações objetivas e subjetivas dos assentados e dos propositores deste projeto será de suma importância para averiguar os enclaves dos embates e desejos destes sujeitos. Assim, verificar as frustações e as expectativas dos assentados sobre a agroecologia dará outro olhar a pesquisa.

A agroecologia pode ser definida como uma série de tentativas sustentáveis e de desenvolvimento de uma agricultura sem o uso de agrotóxicos, porém, no quadro dos movimentos sociais, esta problemática teórica tem levantado inúmeros debates e controvérsias sobre sua base epistemológica.

No entanto, a problemática socioambiental tem orientado a internacionalização de novos valores e princípios que norteiam uma nova racionalidade produtiva sobre bases de sustentabilidade e equidade social. (LEFF, 2002). Neste sentido, práticas agroecológicas, em áreas de reforma agrária, estão sendo desenvolvidas e implantas nos assentamentos rurais.

Diante disso, os contextos a serem exploradas situam-se em proposições de que a agroecologia apresenta fortes características discursivas e de deliberação política pelo MST (Movimento dos Trabalhadores Rurais Sem Terra), como uma maneira de estimular e mobilizar outra forma de viabilização socioambiental e econômica nos assentamentos.

O discurso da agroecologia se estabeleceu no MST com mais ênfase a partir de sua inserção no movimento, o que incluiu uma rede maior de aliados políticos (ONGs Organizações não governamentais, associações, Instituições de Ensino Superior - IES, e órgãos internacionais) e $\mathrm{o}$ acesso às políticas públicas governamentais com foco socioambiental (SOUZA, 2016, p.2).

São apresentadas considerações parciais quanto aos resultados obtidos, tendo como meta responder aos objetivos do estudo e problematizar os aspectos das práticas agroecológicas e a ruptura do projeto inicial, mediante a realidade do assentamento em questão.

\section{A AGROECOLOGIA NA LITERATURA SOCIOLÓGICA}

A literatura sociológica vem ganhando força nas instituições acadêmicas e na sociedade civil, proporcionando um novo olhar para os aspectos ambientais e sociais. Conforme Caporal (2009), a agroecologia, mais do que simplesmente tratar sobre o manejo ecologicamente responsável dos recursos naturais, constitui-se em um campo do conhecimento científico que, partindo de um enfoque holístico e de uma abordagem sistêmica, pretende contribuir para que as sociedades possam redirecionar o curso alterado da 
coevolução social e ecológica, nas suas mais diferentes inter-relações e mútua influência. (CAPORAL, 2009, p.04).

A perspectiva sociológica permite engendrar um campo de disputa nas ciências sociais, possibilitando a construção de uma nova categoria analítica a ser estuda e debatida; pois, conforme Altieri, a agroecologia fornece os princípios ecológicos básicos para o estudo e tratamento de ecossistemas tanto produtivos quanto preservadores dos recursos naturais e que sejam culturalmente sensíveis, socialmente justos e economicamente viáveis (ALTIERI, 1987 apud ALTIERI 2004).

Segundo o contexto literário, o termo agroecologia, no embasamento da perspectiva sociológica, representa um sentido duplo, conforme a teoria do pensamento científico, pois, refere-se à natureza social, com ênfase na ação social coletiva incluindo setores da sociedade civil, conforme afirmativa de Sevilla Guzmán (2002),

\begin{abstract}
la Agroecología se ha ido conformando por iniciativas de determinados grupos campesinos e indígenas, en un proceso de acción social colectiva. Ello tuvo lugar a lo largo de los encuentros que, en distintos territorios latinoamericanos, fueron desarrollándose, desde el comienzo de los años ochenta. Lo iniciaron quienes se autodenominaban "sindicatos revolucionarios campesinos" mediante acciones de convergencia que luchaban por una reforma agraria y contra el acaparamiento de las tierras usurpadas a sus pares, que habían caído en la trampa de los agroquímicos y demás insumos externos, de naturaleza industrial; y habían visto destruidos sus sistemas territoriales de autosuficiencia agroalimentaria (SEVILLA GUZMÁN, 2015, p. 356).
\end{abstract}

Como um sistema ecossociológico, o agroecossistema pode ser compreendido como um ecossistema cultivado, socialmente gerido pela e para a família agricultora; o qual funciona como um concentrado de placenta cultural, de unidade sociológica de base, de provedor econômico e de reprodutor ecológico. Nesse sentido, pode ser interpretado como o resultado do equilíbrio dinâmico entre várias dimensões da vida material e simbólica das famílias agricultoras e suas comunidades.

\footnotetext{
Em função desse caráter dinâmico e multidimensional, qualquer alteração em uma das dimensões implica o deslocamento do equilíbrio do conjunto. Por essa razão, os processos de transformação dos agroecossistemas encerram grande complexidade, cuja compreensão cobra a mobilização e a integração de conhecimentos oriundos das ciências naturais e das ciências sociais (PETERSEN, 2013, p. 85).
}

As ações efetivadas com interação da sociologia e do meio ambiente têm apresentado diversas técnicas de manejo para ampliar o conhecimento dos produtores rurais e recuperar a materialidade da estrutura e da vida social, sendo que envolve a resolução de problemas ambientais. Esta definição reconhece ao mesmo tempo a centralização da verdadeira natureza física do meio ambiente e o papel representado pelas construções sociais da natureza (MCREYNOLDS, 1999).

Neste entendimento, a agroecologia é definida como manejo ecológico dos recursos naturais, tornando-se uma estratégia inovadora frente aos problemas que envolvem a crise da modernidade, provenientes da percepção de que "as sociedades modernas tem avançado tanto na sociedade como na natureza, tendo como delimitação a pesquisa com foco no crescimento econômico equitativo" (SEVILLA GUZMÁN; MIELGO, 1999, p.2); conforme afirmativa:

"Lose" respetar la riqueza privilegiada, utilice la "cortina de humo de la democracia" para justificar el cruel hecho de que los beneficios materiales del crecimiento tan sólo se acumulan en las zonas donde se genera más desigualdad (SEVILLA GUZMÁN; MIELGO, 1999, p.2). 
Neste contexto, nos deparamos com a crise ecológica, em que muitos questionamentos estão sendo analisados com participação da "moderna sociedade", que está investindo no conhecimento científico, portanto, é socialmente construída com recursos naturais,pode ser injetado capital e ser incorporado na dinâmica de desenvolvimento; tornando-se um meio de reduzir as situações problemáticas identificadas nas estruturas "globais" de energia gerada pelos estados comuns transnacionais e por organizações internacionais, como o Fundo Monetário Internacional e o Banco Mundial (SEVILLA GUZMÁN; MIELGO, 1999).

La Agroecología surgió a finales de los años setenta de la pasada centuria, como respuesta a las primeras manifestaciones de la crisis ecológica y social en el campo, generada por la intensificación del desarrollo del capitalismo en la agricultura; que extendía al conjunto del planeta el modelo de la revolución verde, basado en el manejo químico e industrializado de los recursos naturales (SEVILLA GUZMÁN, 2015, p. 353).

Neste entendimento, a agroecologia tornou-se uma prática alternativa de sustentabilidade com embasamento ecológico, com o intuito de explicar o desenvolvimento das características morfológicas e fisiológicas das espécies, conforme assertiva:

\begin{abstract}
Una vez comprobado el deterioro ecológico que ello acarreaba. Como enfrentamiento a esta emergente industrialización agroalimentaria surgió una alianza campesino/indígena con la disidencia a tal agroindustrialización capitalista cuyos modos de participación elaboraron una contundente respuesta. En ella se encontraba: no solo una rigurosa crítica al deterioro ecológico y sociocultural de aquel manejo industrial; sino, también y sobre todo, en la construcción de una sólida alternativa, que adoptó la denominación de Agroecología (SEVILLA GUZMÁN, 2015, p. 353).
\end{abstract}

Portanto, a transformação da natureza e da sociedade envolvem atividades do setor industrial, sendo necessário aplicar ciência e tecnologia nos recursos naturais. Este simples fato nos obriga a identificar e reabilitar os mecanismos de reprodução (SEVILLA GUZMÁN; MIELGO, 1999). Diante disso, a agroecologia tem como finalidade "trabalhar com métodos interdisciplinares adotando diferentes 'formas de conhecimento' que compõem seu pluralismo metodológico e epistemológico, onde a perspectiva sociológica tem um papel central" (SEVILLA GUZMÁN, 2002, p.18).

A agroecologia se depara com alternativas sustentáveis em substituição às práticas predadoras da agricultura capitalista, minimizando assim, "à violência com que a terra foi forçada a dar seus frutos. Com o novo procedimento de plantio e conservação do solo são implementadas as normas e regras para o novo patamar da terra" (LEFF, 2002, p.37).

Assim, a questão da sustentabilidade, depende da resposta da crise de modernidade, incluindo um processo de compromisso entre beneficiários do crescimento econômico e do sistema social da ciência.

Es esencial para la agroecología demostrar la sabiduría como conocimiento contextualizar sistema de campos biofísicos y culturales, tiene el potencial para cumplir con los mecanismos de defensa contra la realidad virtual construida: de este modo el discurso ecotecnocrático como la negación y el conocimiento campesino indígena local, cooptado, irónicamente por ejemplo, para registrar sus derechos de propiedades genéticas en las semillas (GUZMAN; MIELGO, 1999, p.3).

Os aspectos sociais do potencial endógeno devem ser reforçados na dinâmica da luta dos grupos locais que resistem ao processo de modernização industrial dos recursos naturais, conforme defendem Sevilla Guzmán e Mielgo (1999), 
Dimensiones ecológicas se articulan sobre la base de los ecosistemas agrícolas de diversidad genética de estos grupos [y] tienen la intención de mantener; el papel es no sólo [de los] agroecólogos para investigar los aspectos técnicos del potencial endógeno, sino también involucrado en las luchas políticas y éticas, tanto en el centro como en la periferia, [de] los grupos locales (SEVILLA GUZMÁN; MIELGO, 1999, p.3).

Conforme afirmativa a agroecologia caracteriza-se por meio de estruturas e processos ecológicos conquistando assim, "sua reprodução social com ações do social e participação dos movimentos sociais articulados mediante as esferas de alternativas de produção e de circulação" (SEVILLA GUZMÁN; MIELGO, 1999, p.4).

La Agroecología es una construcción popular, surgida de la alianza entre sectores campesinos e indígenas con técnicos (ecólogos, agrónomos, sociólogos y antropólogos) que, con diferente experiencia, vinculada al manejo de los bienes naturales y agrupados en ONG's; fue realizada en Latinoamérica, a través de una dinámica participativa en la que, a agrandes rasgos, pueden diferenciarse tres etapas, conforme afirmación de Guzmán (2015)

La primera se extiende a lo largo de los años 80's de la pasada centuria y se podría calificar como etapa de resistencia y construcción participativa campesino/indígena.

La segunda es la etapa de hibridación tecnológica y propuesta socioeconómica, donde se consolida y formaliza el "diálogo de saberes", ya iniciado en la articulación campesino/indígena; y se construye una alternativa a la agricultura industrializada y su sistema agroalimentario global; ocupando temporalmente los últimos años de la primera etapa y la totalidad de la década de los 90's.

La tercera etapa que, con unos límites exibles abarca la primera década del 2000; puede ser definida, como etapa de construcción participativa de propuestas de liberación sociocultural y política, por su articulación con los movimientos sociales y la generalizada aceptación académica (SEVILLA GUZMÁN, 2015, p. 355).

Com os movimentos sociais articulados, os conhecimentos dos assuntos referentes aos saberes agroecológicos foram aprofundados e novas técnicas foram aplicadas ao campo, obtendo-se resultados positivos às condições ecológicas, econômicas e culturais de cada região geográfica e de cada população. Estes saberes e estas práticas não se unificam em torno de uma ciência: as condições históricas de sua produção estão articuladas em diferentes níveis de produção teórica e de ação política, buscando inovações para a aplicação de métodos orgânicos. A agroecologia, como reação aos modelos agrícolas depredadores, configura-se por meio de "um novo campo de saberes práticos para uma agricultura mais sustentável, orientada ao bem comum e ao equilíbrio ecológico do planeta, tornando-se uma ferramenta para a auto subsistência e segurança alimentar das comunidades rurais" (LEFF, 2002, p.37).

\footnotetext{
El marco teórico de la sociología agraria de las sociedades avanzadas desarrolla una metodología explicativa de la coexistencia de formas de explotación campesinas e industriales. Parte del concepto de producción simple de mercancías agrarias, en regímenes agroalimentarios globales que dan cuenta de la expansión histórica del capitalismo manteniendo elementos tautológicos que solo comienzan a cuestionarse con la aparición de la fértil herramienta analítica elaborada por la Escuela de Wageningen de los Styles of Farming. Esta culminaría con Jan Douwe van der Ploeg, en su tardio descubrimiento de lo endógeno, de naturaleza agroecológica; dando pie a la acertada crítica de la perversidad del sistema agroalimentario global, que trascendería el pensamiento convencional con la transgresión alternativa de los imperios agroalimentarios y la respuesta de campesinización (SEVILLA GUZMÁN, 2013, p.94).
}

Conforme afirmativa entende-se que a cultura coevoluciona com a natureza, hibridando-se e diversificando-se, multiplicando os sentidos da vida e as formas da natureza; recupera a atividade do camponês; ampliando assim seu meio de subsistência com a 
articulação das relações de complementaridade e reciprocidade, deixando de lado o interesse mercantil (LEFF, 2002).

Neste ponto de vista, qualquer agricultor, enquanto empreendedor econômico, poderia simplificar sua atividade, em contraste com a demanda ambiental de maior complexidade como forma de manter a sustentabilidade, desprezando as experiências seculares das sociedades camponesas tradicionais (ROMEIRO, 1998).

Além disso, a complexidade relativa das sociedades camponesas tradicionais apresentava-se como um ônus para o processo de intensificação da produção agrícola, que a partir de sua simplificação viabilizou a obtenção de grandes extensões de terra, sob a justificativa da necessidade de ganho de escala como única forma de aumentar a produção de alimentos e, assim, solucionar o problema da fome. A partir do final da década de 80, esse processo se mostrou extremamente danoso, para os países subdesenvolvidos. A ligação entre agricultura e meio ambiente foi, até o fim dos anos 80, um assunto tabu, no qual os problemas ambientais eram apenas industriais, urbanos e ecológicos (ASSIS, 2003).

A manutenção e a melhoria das reservas de nitrogênio no solo, bem como o seu suprimento às plantas cultivadas representam grandes desafios da agricultura orgânica (ALTIERI, 1989). Em experimentos efetivados em sistemas orgânicos, a adubação foi adotada como fonte de nutrientes para as plantas, principalmente o esterco bovino e a cama de aviário. Entretanto, estudos demonstraram a necessidade de utilização de grandes quantidades desses materiais (OLIVEIRA, 2001), o que limita sua aplicação em virtude do reduzido número de criações conduzidas de acordo com os preceitos da produção orgânica.

Com o novo panorama, o cultivo da soja como adubo verde, especialmente em sistemas de produção de alta rotatividade de culturas, pode representar importante fonte de nitrogênio fixado biologicamente ao ser aportado aos sistemas de produção.

A agricultura orgânica tem por princípio estabelecer sistemas de produção com base em tecnologias de processos, ou seja, um conjunto de procedimentos que envolvam a planta, o solo e as condições climáticas, produzindo um alimento sadio, com características e sabor originais e que atenda às expectativas do consumidor (PENTEADO, 2000).

Assim, a agroecologia, com embasamento nos princípios da produtividade ecotecnológica, oferece novos potenciais para o desenvolvimento sustentável alternativo. As práticas agroecológicas resultam culturalmente compatíveis com a racionalidade produtiva camponesa, pois, constroem-se sobre o conhecimento agrícola tradicional, combinando este conhecimento com elementos da ciência agrícola moderna (LEFF, 2002).

A ciência moderna envolve o processo de conversão ou transição agroecológica para viabilizar a consolidação do modelo sustentável de produção rural. A compreensão dos processos agronômicos, biológicos, ecológicos, econômicos e socioculturais significa o redesenho dos sistemas de produção, considerados imprescindíveis para o sucesso da conversão de práticas convencionais agroecológicas (EMBRAPA, 2004).

Neste sentido, a agroecologia tornou-se uma base de pesquisa para o estudo integrativo da ecologia do sistema alimentar como um todo, que abrange desde a apropriação da natureza até o consumo. Ou seja, efetiva-se com um esforço de construção de modelos de agricultura e de sociedade, em que as externalidades negativas, sejam eliminadas, como por exemplo, exclusão social no campo, a dependência de insumos químicos, os impactos ambientais, o uso insustentável dos recursos naturais, a contaminação ambiental e dos alimentos (FRANCIS et al., 2003).

Neste processo agroecológico, as técnicas adotadas seguem teorias desenvolvidas que permitem o aproveitamento de recursos naturais, bem como, seguem a otimização da unidade de produção, por meio da incorporação de novos elementos que fazem parte das práticas tradicionais de manejo, elevando a produtividade e preservando a capacidade produtiva sustentável do ecossistema (EMBRAPA, 2004).

Os agroecossistemas se concretizam com a evolução dos grupos sociais, situando-se nas formas de conhecimento, organização, tecnologias e valores. Sistemas nos 
quais os ciclos minerais, as transformações de energia, os processos biológicos e as relações socioeconômicas devem ser investigados (ALTIERI, 1992).

[...] [o] pensamento social agrário dominante, cada vez mais se torna defasado e inoperante para explicar os fenômenos sociais no mundo rural contemporâneo, envolvendo as estratégias adotadas na agricultura camponesa que persevera e se renova continuamente. Dentre as razões para essa defasagem, pode-se apontar o conceito de camponês, ou seja, o camponês feudal (PETERSEN, 2013, p. 97).

Neste entendimento, a agroecologia corresponde ao desafio de implementar estratégias que permitam o conhecimento da agricultura como uma disciplina interdisciplinar que envolve cultura e ambiente natural desde uma perspectiva histórica, para obter do agroecossistema em questão, o equilíbrio original, conforme afirmativa de Wanderley (2009, p.87), "[...] a reprodução do camponês sob o capitalismo passa por um novo crivo, o das leis do funcionamento do capital. Considera o camponês algo novo, criado pelo capital e que precisa ser compreendido nesta sua nova condição".

Portanto, cada agroecossistema tem um potencial local que surge da articulação histórica de cada pedaço da natureza e da sociedade, este potencial tende a ser degradado e destruído, tanto em seus aspectos sociais e ecológicos, quanto pela modernização industrial. Ou seja, a agroecologia procura usar e desenvolver este potencial e reforça a dinâmica da luta dos grupos locais que resistem ao processo de modernização industrial dos recursos naturais (SEVILLA GUZMÁN, 1999).

A agroecologia desenvolve suas propostas com o intuito de buscar formas alternativas de comercialização dos produtos, permitindo melhores condições de construção de mercados por parte dos agricultores e, por outro lado, "possibilitar maiores condições de acesso aos alimentos ecológicos por parte dos consumidores, além de construir processos alternativos aos padrões dominantes no sistema agroalimentar contemporâneo" (NIEDERLE; ALMEIDA; VEZZANI, 2013, p. 174).

Se a agricultura como um todo deve tornar-se verdadeiramente sustentável, todos os aspectos da produção, distribuição e consumo de alimentos precisam estar incluídos, pois, significa transformar os sistemas globais de produção, processamento e distribuição de alimentos, os quais se estendem a quase todos os aspectos da sociedade humana e do ambiente construído (GLIESSMAN, 2009, p. 595).

Portanto, a proposta da agroecologia torna-se uma ferramenta relevante para colocar em prática os conceitos que envolvem a agricultura familiar e camponesa, a sustentabilidade ambiental e a equidade nas relações de mercado, tornando-se pré-condições para a estruturação de sistemas agroalimentares que garantam o direito humano à alimentação adequada (SEVILLA GUZMÁN; SOLER, 2010).

Sob essa perspectiva, compreende-se que os assentamentos rurais são reconhecidos como espaços sociais privilegiados, tanto de produção discursiva, em relação à agroecologia, quanto para o desenvolvimento das práticas agroecológicas, pois é um dos principais lugares onde está localizada a base social do MST.

Neste sentido, esta pesquisa visa compreender as práticas agroecológicas e a constituição de um paradigma de agricultura sustentável implantada no assentamento Ander Rodolfo Henrique. Anseia ainda entender quais foram os limites e as controvérsias no desenvolvimento deste projeto de assentamento. Para tanto, busca-se problematizar a ruptura de um modelo de produção agroecológica, que estava em construção, e verificar quais foram os elementos chaves que causaram o rompimento deste projeto.

\section{PROCEDIMENTOS METODOLÓGICOS}


A pesquisa de campo envolveu 46 (quarenta e seis) famílias da população do assentamento Ander Rodolfo Henrique situado nos municípios de Diamante D’Oeste e Vera Cruz do Oeste, local administrado pelo Instituto Nacional de Colonização e Reforma Agrária - INCRA.

A coleta dos dados possibilitou a observação empírica dos sujeitos que interagem junto ao espaço social do MST e, por meio destas percepções e da captação do discurso enunciado em seu contexto de atuação política, foi possível coletar opiniões, visões e expectativas em relação à agroecologia; resgatar compreensões e fatos em relação aos sistemas de produção adotados anteriormente no MST e entender e descrever como está se constituindo as ações em agroecologia junto ao movimento conforme o discurso destes sujeitos.

Para a compreensão dos eixos norteadores teórico-ideológicos do MST, foi realizada análise documental por meio da coleta de dados secundários produzidos pelo MST sobre o assentamento pesquisado, desde sua fundação em 2002 até 2015. Para tanto, analisaram-se cartilhas, cadernos de formação, revistas, boletins públicos do movimento, livros, documentos internos (atas das reuniões do assentamento, regimento interno, Plano do Desenvolvimento sustentável, arquivos individuais, como fotos e estória oral das famílias), arquivos da biblioteca do Instituto Técnico de Pesquisa e Reforma Agrária (ITEPA) localizado no município de São Miguel do Iguaçu-PR e textos publicados na página da Internet do movimento. Além disso, será efetivada coleta de dados primários, com base em informações recentes do MST, apresentando as novas diretrizes do movimento com as ações agroecológicas. Esta técnica constitui-se, segundo Ludke e André (1986), ferramenta importante para a coleta de dados em pesquisas de caráter qualitativo.

Diante disso, pretende-se verificar como são construídas as novas práticas produtivas, neste assentamento, e quais são as inter-relações estabelecidas entre os assentados na produção destas práticas. Nesse sentido, o foco do estudo envolve o construtor de realidades sociais e históricas na construção destas ações. Pretende-se resgatar a ideia de sentido dado aos sujeitos às suas ações, ou seja, o sentido mentalmente construído individualmente por estes sujeitos, em suas atividades na produção agroecológica, no assentamento em estudo.

\section{RESULTADOS E DISCUSSÕES: UMA ANÁLISE EM CONSTRUÇÃO}

No que se refere à agroecologia, no assentamento Ander Rodolfo Henrique, há diversos elementos a serem analisados e problematizados para a compreensão das representações objetivas e subjetivas em torno do projeto alicerçado a partir de 2002 e seu rompimento em 2013.

Entender agroecologia como uma superação do paradigma atual de agricultura envolve conhecer suas definições para então consolidar este novo ideal de agricultura. $\mathrm{O}$ entendimento e as percepções dos assentados-camponeses em torno à agroecologia remetem a interpretações e codificações dos espaços do assentamento, principalmente quando o PDA exige que as famílias, desde o início da sua implantação, façam um rompimento "brusco" e definitivo com as estruturas da agricultura mercadológica expropriadora dos recursos naturais e inicie uma nova representação de mundo entre famílias camponesas-assentadas e a produção de alimentos livres de agrotóxicos e sementes transgênicas.

Neste sentido, o condicionamento das famílias camponesas assentadas ao projeto desenvolvido, cuja matriz era em agroecologia, envolvendo sustentabilidade ambiental, social e econômica, não considerou a multiculturalidade e a subjetividade dos sujeitos que compõem a comunidade do assentamento rural Ander Rodolfo Henrique. Conforme Bauman (2003),

Contribui para pensar essa questão ao discutir as ambiguidades do conceito de comunidade e estabelecer a distinção entre comunidade ética - cujo entendimento entre os membros é natural e compartilhado, ponto de partida (e não de chegada) 
para a união, a despeito de todos os fatores que possam contribuir para a separação e comunidade estética-cuja natureza superficial e transitória dos laços torna-os pouco duradouros e não cria entre seus membros uma rede de responsabilidades éticas e de compromissos de longo prazo. (BAUMAN, 2003, p.20).

Scopinho (2009) afirma que estas comunidades (a ética e a estética) são produtos dos tempos atuais, cuja velocidade das mudanças impõe um ritmo também muito rápido no modo como os sujeitos constroem vínculos por meio dos quais eles identificam-se e mantémse como grupo organizado em torno de um determinado projeto de vida e de trabalho. Para Scopinho, Bauman identifica bem este comportamento dos sujeitos expostos a determinadas situações,

O autor define identidade como algo que "[...] só nos é revelada como algo a ser inventado, e não descoberto, como alvo de um esforço, 'um objetivo' [...]" (BAUMAN, 2005, p. 21-22). Nesse sentido, identidade é preparação, identificar-se com “[...] significa dar abrigo a um destino desconhecido que não se pode influenciar, muito menos controlar. Assim, talvez seja mais prudente portar identidades [...] como um manto leve pronto para ser despido a qualquer momento" (BAUMAN, 2005, p. 36-37). Em suma, identidade está sendo entendida aqui como produto da relação que o sujeito estabelece, em um determinado tempo e espaço, com as estruturas sociais às quais ele está vinculado. (SCOPINHO, 2009, p.259)

Segundo (BOURDIEU, 1997, apud SCOPINHO, 2009), é necessário fazer um esforço para entender o sujeito desde onde ele se encontra na estrutura social. Neste sentido, fizemos esforços para tentar compreender o perfil sociocultural das famílias e analisar as prováveis relações que permeiam os sentidos atribuídos à agroecologia.

Ao analisarmos a realidade do assentamento, nos deparamos com uma pluriatividades de interesses individuais que, muitas vezes, não representa os ideais da organização e produção do MST. Neste sentido, a reforma agrária, nos projetos agroecológicos, necessita ter certos cuidados, problematizar dados conceitos para evitar determinados paradoxos, muitas vezes utópicos.

A demanda por se forjar projetos de assentamentos sustentáveis, sobrecarrega aos próprios sujeitos que estão fragilizados pelas estruturas do Estado e da agricultura mercadológica do Agronegócio. Como Afirma Scopinho, os assentamentos muitas vezes vivenciam;

a construção de outras relações sociais, porém, vivenciam também a contraditória realidade da política de reforma agrária brasileira, cuja marca é a fragmentação e a desarticulação das políticas públicas e ações governamentais voltadas para a implantação dos projetos de assentamento. Sob a custódia do Estado, reproduz-se nos assentamentos rurais agroecológicos, exatamente, o projeto hegemônico de sociedade que com eles se quer negar (SCOPINHO, 2007, p. 20).

Notamos, no decorrer da pesquisa, que este projeto de assentamento em seu contexto histórico, teve seus alicerces impostos por seus propositores; pois os assentados aderiram ao modelo agroecológico como uma dívida moral.

Segundo Lazzaretti (2007 apud SOUZA, 2016), os assentados possuem uma dívida moral com o MST gerada por uma relação de reciprocidade assimétrica produzindo respeito, obediência e dependência.

A seguir apresentamos esquema que representa esta dívida moral entre os agricultores e o MST.

Esquema 1 - Representação da dívida moral dos agricultores-camponeses 


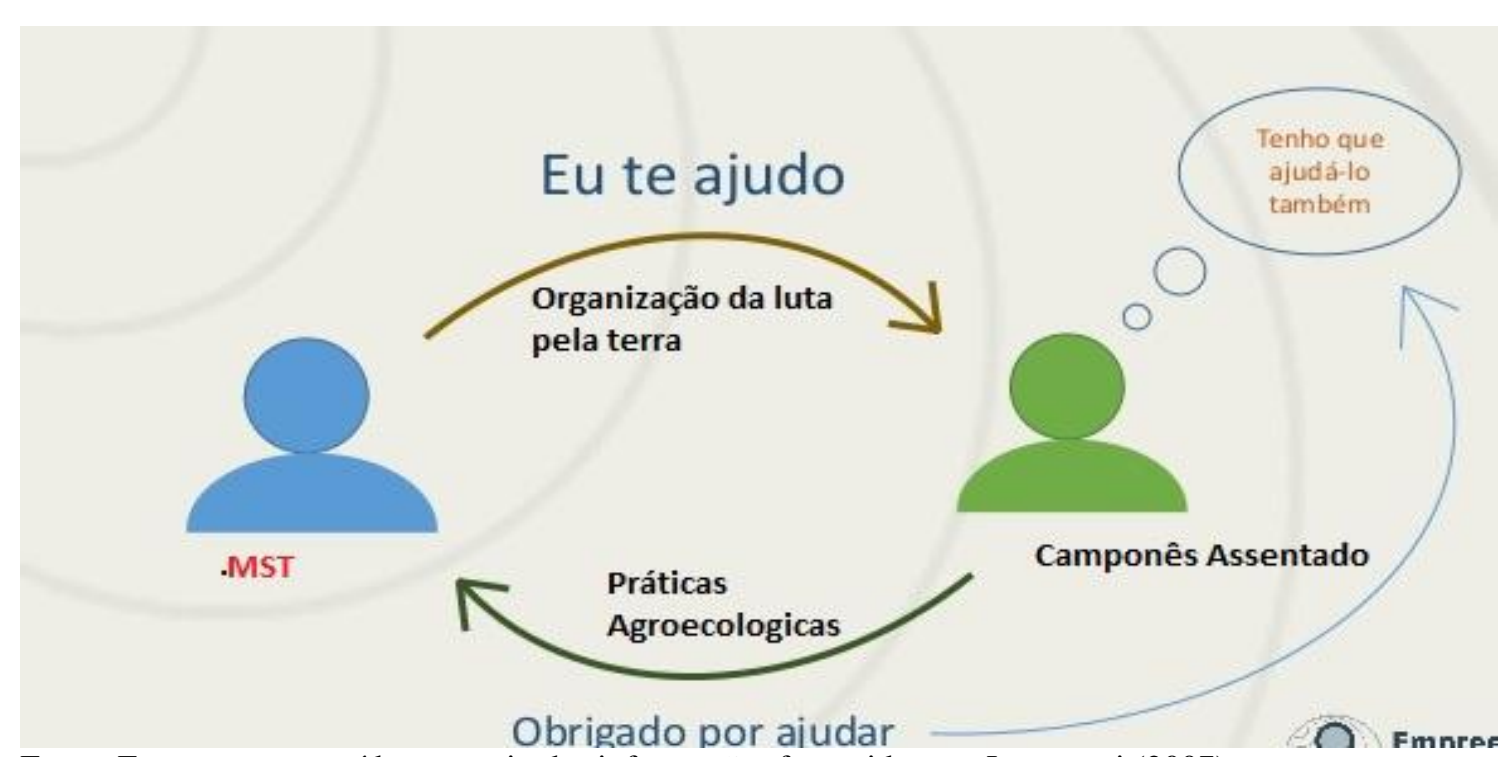

Fonte: Esquema construído por meio das informações fornecidas por Lazzaretti (2007).

Gouldner (1960), em The norm of reciprocity, analisa a reciprocidade enquanto norma moral. Trata-se, para ele, de uma norma generalizada e universal, essencial à manutenção de estruturas sociais e de sistemas sociais estáveis. Simmel (1896) foi o primeiro sociólogo a tratar da importância da reciprocidade como fundamento das relações sociais, ele considera a reciprocidade das prestações como essencial à coesão social, inclusive nas sociedades contemporâneas. Neste sentido, mesmo não tendo ideia formada em torno da agroecologia, os assentados aderiram este projeto de desenvolvimento sustentável de base agroecológica. Com o passar dos anos a obediência e a dependência para com os ideais do MST foram desaparecendo e os laços de reciprocidade, conforme os autores (Gouldner,1960; Simmel,1896; Lazzaretti,2007), foram se distanciando e gerando outras formas de relações entre os membros da comunidade e os representantes do MST.

Segundo Souza (2016), hoje, a realidade do assentamento é totalmente oposta, muitas famílias se voltaram à produção convencional, impulsionada pelo aparato financeiro oferecido pelos complexos agroindustriais que "rodeiam" o assentamento, oferecem subsídios de custos para a produção da safra agrícola com garantias de preço e compra de suas produções. Souza afirma que,

O fator cultural também influenciou nas tomadas de decisões no presente e no futuro, pois, conforme literatura, o agricultor familiar-camponês tem seu próprio modo de vida no campo (LAZZARETTI, 2007; ABRAMOVAY, 1998; KAUSTSKY, 1980; FABRINI, 2002) muitas vezes já desestruturado pelo modelo agrícola vigente e, neste sentido, a adesão ao modo de trabalho voltado à agroecologia seria novamente mais um modelo imposto. Observa-se, que além dos fatores puramente econômicos, inclui fatores culturais, sociais, religiosos e outros que correspondem aos anseios destes sujeitos. (SOUZA, 2016, p.16).

As famílias dos camponeses-assentados são, majoritariamente, oriundas dos estados do Sul do Brasil (RS, SC e PR) que percorreram as fronteiras agrícolas, entre 1980 e 1990, em busca de um sonho por uma vida melhor no Paraguai. Conforme gráfico 1, observamos que mais de $60 \%$ dos entrevistados já moraram no país vizinho. Mas este sonho acabou frustrado pela própria dinâmica de política agrícola que o Estado exerce para com seus agricultores-campesinos, que não vem ao caso exploramos. 
Título

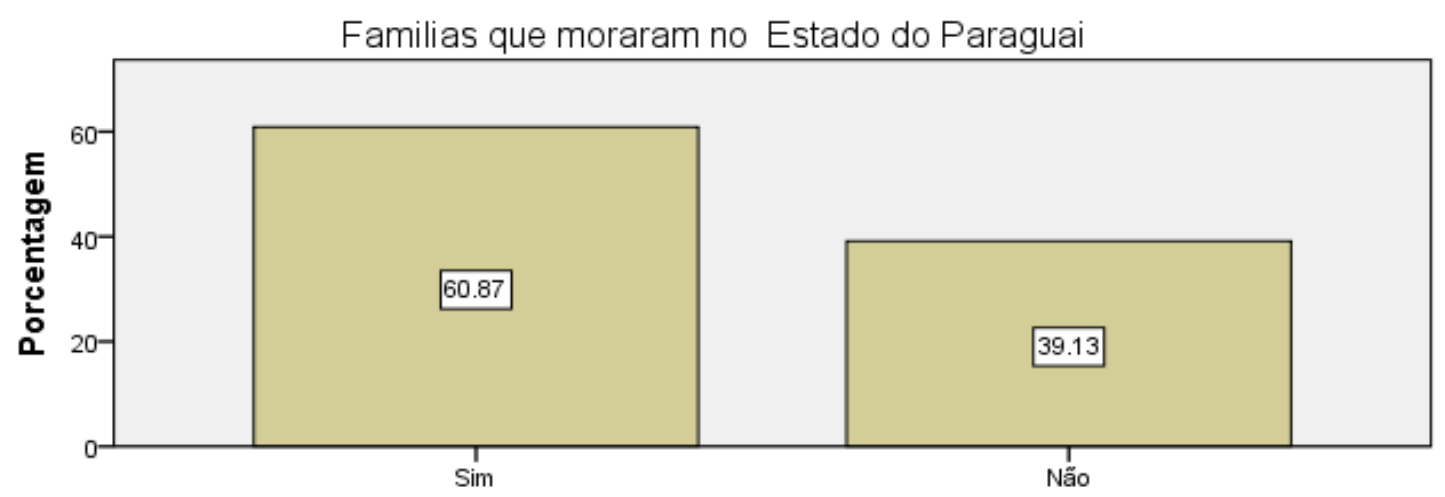

Fonte: Dados da pesquisa, 2016.

De acordo com Ferreira et al. (1998), "a diversidade sociais em que se encontram os agricultores, a partir da forma de inserção nesse duplo processo de modernização/exclusão, também foi acompanhada por uma forte transformação do meio ambiente, tanto pelo impacto do modelo tecnológico que lhe é subjacente sobre os recursos naturais como no sentido social” [...] (FERREIRA,1998, p.20).

Para Scopinho (2009), "se o projeto de assentamento, fruto de um acordo, configurou-se como um misto de comunidade rural acrescida da ideia de sustentabilidade contida no PDS, os seus construtores eram portadores de uma história cuja característica marcante é a diversidade sócio-cultural." (SCOPINHO, 2009, p.269).

Durante a pesquisa, percebemos que, dentre os motivos para se ingressar em uma ocupação do MST, o sonho por um pedaço de terra para a sobrevivência predominou no anseio das famílias entrevistadas, na árdua luta contra o capital, famílias estas, desestruturadas pelo modelo agrícola vigente. Conforme observamos no gráfico abaixo: 


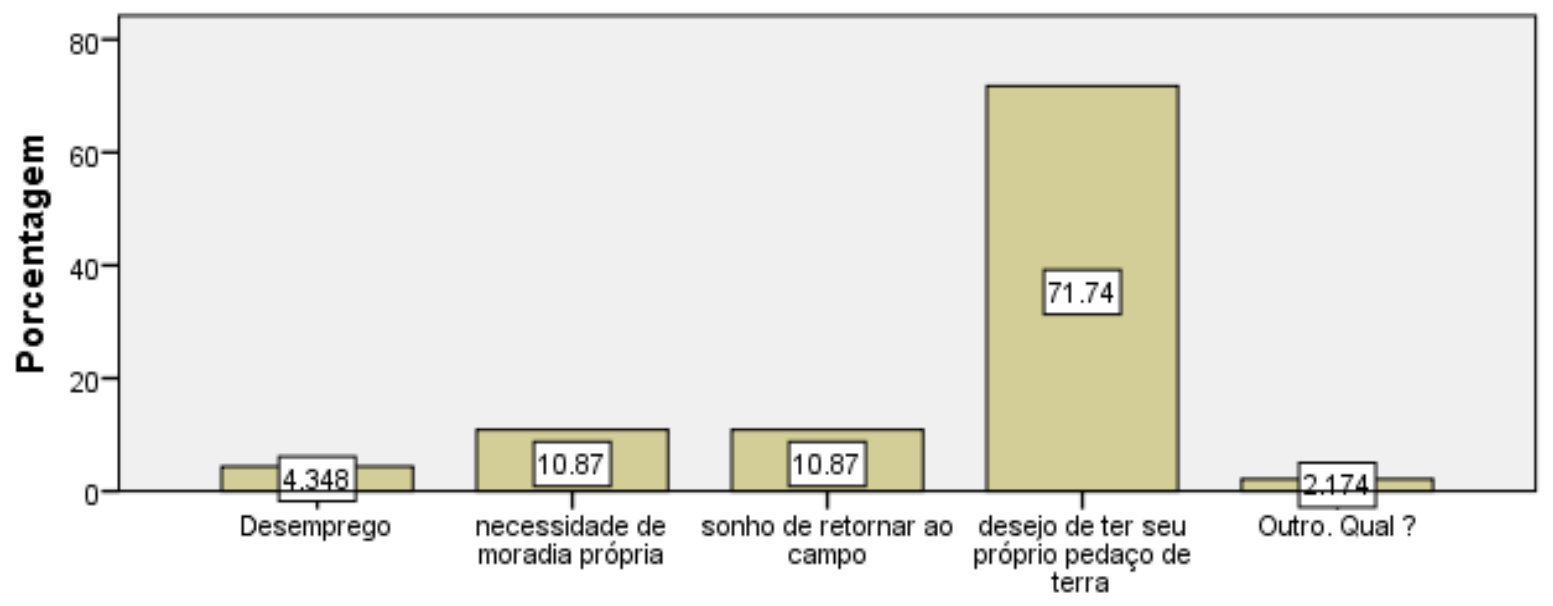

Fonte: Dados da pesquisa, 2016.

O sonho se concretizou, estas famílias têm ou tiveram um pedaço de terra para sobreviver, porém esta realidade é contraditória, pois a reforma agrária deveria representar, nos espaços de assentamentos, um salto de qualidade de vida e bem estar social, para impulsionar os anseios dos assentados, entretanto este sonho não chegou a sua plenitude, por diversos fatores. A viabilidade econômica da reforma agrária, como política de superação de combate à pobreza, não se concretizou para muitas famílias.

O Assentamento Ander Rodolfo Henrique representa esta realidade, dados da pesquisa mostram que o projeto de agroecologia que seria para estruturar a viabilidade econômica das famílias assentadas, não está representando o ideal proposto, pois, na realidade concreta do assentamento, a maiorias dos filhos (em muitos casos os titulares dos lotes) dos assentados tem trabalhando fora do assentamento para conseguir sobreviver e manter as necessidades básicas de sua família, conforme aponta gráfico 3; esta realidade é extremamente conflitante, para os dados da reforma agrária.

Gráfico 3 - Membros da família que estão empregados fora do assentamento.

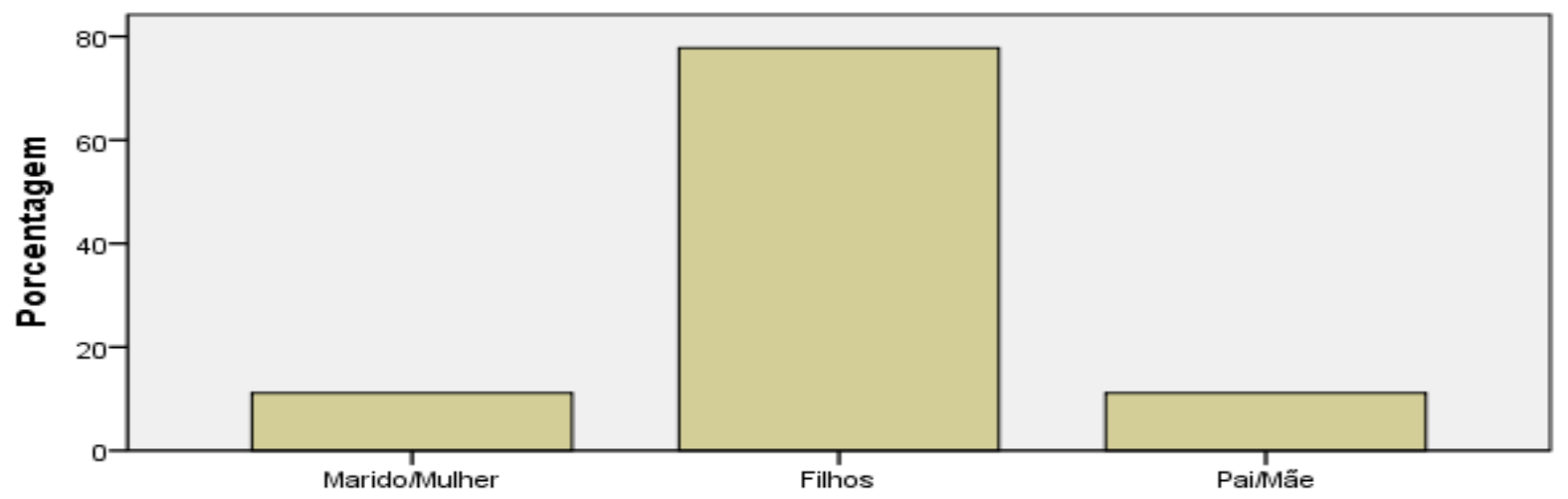

Fonte: Dados da pesquisa, 2016.

Segundo Souza (2016), dos entrevistados, 30,4\% ou 14 dos 46 declararam que os filhos trabalham fora do assentamento. Deste modo, as famílias estão perdendo a força de trabalho destes jovens, que poderiam contribuir com o desenvolvimento econômico e social familiar. No entanto, o assentamento, para estes jovens, é apenas um lugar para morar e 
descansar aos finais de semanas, pois não têm perspectivas de crescimento econômico e bem estar social. Neste sentido:

As condições de realização do trabalho no assentamento não favoreciam o desenvolvimento da cooperação autogestionária como forma de superar esses impasses. Pelo contrário, a falta de capital, de infraestrutura (principalmente água) e de orientação técnica para realizar a agroecologia e as restrições impostas pelo (Termo de compromisso e o PDA) condicionavam um jeito de fazer a economia do assentamento funcionar que levava os assentados a "dar uns pulos" para sobreviver. (SCOPINHO, 2009, p.268).

Para Souza (2016), outro fator que desencadeou o processo de ruptura do projeto agroecológico seria a viabilidade econômica das famílias em produzir de forma sustentável. De acordo com dados do gráfico 4, observamos que quase $60 \%$ das famílias assentadas têm renda de 2 a 3 salários mínimos, sendo que 4,35\% recebem menos de um salário mínimo e pouco mais de $6 \%$ por cento, até um salário mínimo; isto denota que quase $70 \%$ das famílias têm renda de no máximo 3 salários mínimos. Em se tratando de famílias que trabalham com a terra este valores são pequenos.

Gráfico 4 - Renda média das famílias

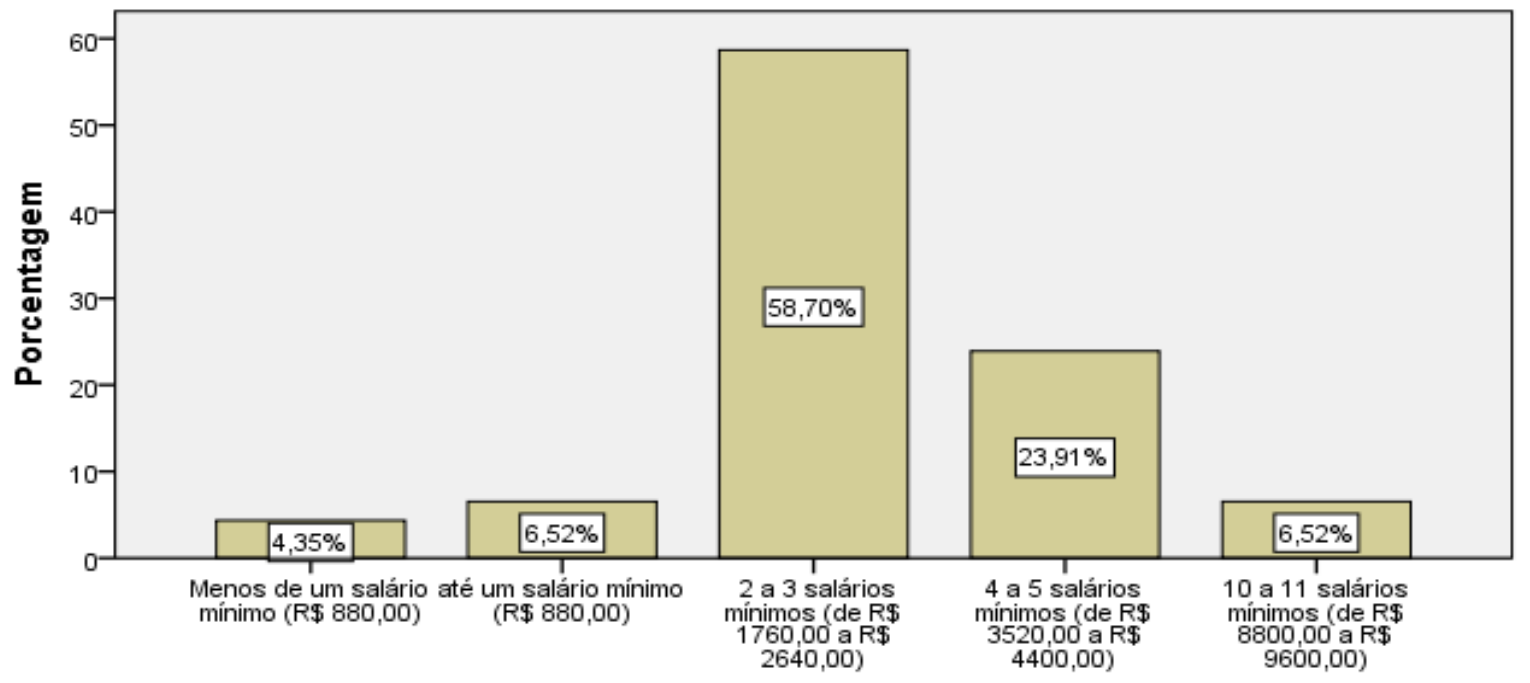

Fonte: Dados da pesquisa, 2016.

Segundo informações de campo, os grupos articuladores, que estruturaram a matriz tecnológica de produção agroecológica, não projetaram meios de escoamento da própria produção, desde a certificação de suas propriedades até a comercialização. Várias famílias começaram a criticar a estrutura organizativa do projeto de assentamento, em torno da matriz tecnológica de produção agroecológica. Desta maneira,

O modelo adotado não estava correspondendo às expectativas das famílias em relação à viabilidade econômica, pois elas produziam alimentos livres de agrotóxicos, no entanto, vendiam como convencional às cooperativas agroindustriais. Após romperem com o projeto agroecológico, a renda das famílias continua a ser um fator decisório para o desenvolvimento econômico. Mesmo no modelo convencional de produção agropecuária $82,61 \%$ das 46 famílias entrevistadas estão na faixa salarial de 2 a 5 salários mínimos. Isso remete a uma renda bruta mensal, sem analisarmos os custos de produção e outros fatores que fragilizariam ainda mais o fator econômico das famílias. (SOUZA, 2016, p.16). 
Devido ao modo como foi conduzido o PDA do assentamento, vários aspectos impulsionaram o rompimento da matriz tecnológica agroecológica, conforme aponta análise da literatura sobre o assunto: Guzmán Casado e González de Molina; Sevilla Guzmán, 2002; Altieri, 1989; Caporal; Costabeber, 2004; Souza, 2016, Gliessman, 2009; Sevilla Guzmán e Soler, 2010; Mcreynolds, 1999; Leff, 2002; Scopinho, 2009.

A agroecologia não pode ser conduzida como uma punição (de cima para baixo) aos agricultores e familiares-camponês com o intuito de se construir um ideal de agricultura que rompe com o paradigma dominante; pois, deste modo, a culpabilidade do fracasso recai sobre os assentados da reforma agrária, porém, diversos são os fatores necessários para impulsionar o desenvolvimento da matriz agroecológica.

Ao se trabalhar com projetos de desenvolvimento sustentável, muitas vezes, os próprios movimentos sociais do campo, impõem uma realidade que não condiz com as representações dos sujeitos que estão na labuta do dia-dia. Conforme análise do regimento interno do assentamento percebe-se a imposição de regras e normas, sendo a agroecologia um compromisso a ser exercido no decorrer dos anos, responsabilidade que deveria ser do Estado; pois, quem destruiu a biodiversidade do ecossistema do assentamento foi o latifúndio que gere os espaços que hoje constituem o assentamento.

\footnotetext{
Na linha de produção agrícola, fica definida a proibição de uso de qualquer produto químico, quer seja na lavoura ou pastagens, açudes, gado de leite e corte e animais como galinhas, porcos entre outros. A mesma definição deverá ser respeitada por todos sem escenção [sic]. Pois, as famílias optaram pela linha de produção $100 \%$ orgânica. Cabendo a todos reflorestar e proteger as nascentes, o meio ambiente de maneira geral. (REGIMENTO INTERNO DO ASSENTAMENTO ANDER RODOLFO HENRIQUE, 2003).
}

Corroboramos a Scopinho et al. (2016), pois entendemos os assentamentos rurais como espaços sociais, no sentido dado por Bourdieu (2001), onde as interações dos agentes é permeada não somente de consensos, mas também por conflitos e contradições, cujo processo organizativo deve considerar as regras formais e as singularidades presentes no cotidiano dos trabalhadores. (SCOPINHO et al 2016, p.44).

Conforme afirma Ferreira et al (1998), “a questão da viabilização de um novo modelo de desenvolvimento rural está novamente em pauta do dia [...]. Isso significa repensar o rural como espaço de outras agriculturas e também como espaço de vida, trabalho e de lazer [...]. Não se trata, pois de um 'problema rural', mas de uma 'questão de sociedade', no âmbito da qual a reflexão sobre 'outra agricultura' pode ser empreendida para se avaliar, sobretudo, a construção de novos espaços e possiblidades de reprodução e integração social”. (FERREIRA et al ,1998, p.21-23).

\section{CONSIDERAÇÕES FINAIS: UM BALANÇO AINDA ABERTO}

Considerações preliminares apontam que o projeto de desenvolvimento sustentável, com proposta de uma matriz agroecológica baseada nos princípios de sustentabilidade ambiental, social, econômica e cultural, não representou o anseio das famílias camponesas assentadas.

Conforme observações dos dados de campo e informações da bibliografia estudada, a agroecologia, para estes assentados, tornou-se uma medida punitiva para o enquadramento do projeto que estava se almejando. Ou seja, há uma ligação social, afetiva ou simbólica, certamente assimétrica, mas criadora de laços de reciprocidade que precisaremos aprofundar no decorrer da pesquisa para averiguar as externalidades dos sistemas sociais existente no assentamento. 
A distância das representações objetivas e subjetivas dos assentados e dos organizadores sobre a agroecologia remete a uma reflexão, muitas vezes assimétrica; pois de um lado está o MST com o modelo agroecológico e de outro os assentados que se veem obrigados a aderir à proposta, como pagamento de uma dívida moral ao movimento social.

Podemos afirmar que as expectativas dos assentados, quanto ao projeto agroecológico, foram frustradas por diversos fatores. Visto que as dificuldades apresentadas no cotidiano dos assentados na vivência com a agroecologia e na falta de acesso a recursos financeiros, desencadearam o rompimento do PDA e frustações das ações e práticas agroecológicas, levando a um desencantamento do modelo agroecológico, permeando apenas uma visão utópica de seus propositores sem eficiência na prática e na construção de um novo paradigma de agricultura sustentável.

Outro fator que culminou com a desestruturação do modelo agroecológico é a reproletarização dos filhos dos assentados camponeses (em muitos casos os próprios titulares do lote) nos complexos agroindustriais, o que causa o aumento, do tempo de trabalho no lote para o desempenho das atividades agrícolas.

A necessidade de se pensar qual "agricultura queremos" ultrapassa os limites e anseios de determinados grupos sociais, precisamos reorganizar os valores da reciprocidade do homem do campo para se pensar as potencialidades de desenvolvimento da produção da agricultura familiar-camponesa em bases agroecológicas.

A agroecologia necessita de reformulações dos espaços agrários e das políticas públicas para um eficaz desenvolvimento rural sustentável, para permear a emancipação do homem do campo edificando novos valores sociais e ambientais para um pleno equilíbrio entre ser humano e natureza.

\section{REFERÊNCIAS}

ALTIERI, M. A. Agroecologia: as bases científicas para a agricultura alternativa. Rio de Janeiro: Projeto e Tecnologias Alternativas/FASE, 1989.

Biodiversidad, agroecología y manejo de plagas. CETAL: Valparaíso, 1992.

Agroecologia: a dinâmica produtiva da agricultura sustentável. 4.ed. Porto Alegre:

UFRGS, 2004.

ASSIS, Renato L. de. Globalização, desenvolvimento sustentável e ação local: o caso da agricultura orgânica. Cadernos de ciência e tecnologia, Brasília, v. 20, n.1, jan/abr. 2003, p. 79-96.

BAUMAN, Z. Comunidade: a busca por segurança no mundo atual. Rio de Janeiro: Zahar, 2003.

BOURDIEU, P. Compreender. In: P. Boudieu et al. (Orgs.). A miséria do mundo. 4.ed.Petrópolis: Vozes, 1997. p. 693-713.

CAPORAL, F.R. Agroecologia: uma Nova Ciência para Apoiara Transição a Agriculturas mais Sustentaveis.1.ed.Brasilia:MDA/SAF, 2009.v.1.30p.ISBN:978-85-60548-70-5

CAPORAL, F. R.; COSTABEBER, J. A. Agroecologia: alguns conceitos e princípios. Brasília:MDA/SAF/DATER-IICA. 2004b

EMBRAPA - Empresa Brasileira de Pesquisa Agropecuária. Ministério da Agricultura, Pecuária e Abastecimento. Marco referencial em agroecologia. Brasília, DF: Embrapa Informação Tecnológica, 2006. 
FERREIRA, Angela Duarte Damasceno et al. Para pensar: outra agricultura. Curitiba: Editora da UFPR, 1998.

FRANCIS, C. et al. Agroecology: The Ecology of Food Systems. Journal of Sustainable Agriculture, v.22, n.3, 2003, p. 99-118.

GLIESSMAN, S. R. Agroecologia: processos ecológicos em agricultura sustentável. Porto Alegre: Editora da UFRGS, 2009.

GOULDNER, A. W. The Norm of Reciprocity. American Sociological Review, v.25, n.2, April, 1960. p.161-178.

GUZMÁN CASADO, G.; GONZÁLEZ DE MOLINA, M.; SEVILLA GUZMÁN, E. (coords.).Introducción a la Agroecología como desarrollo rural sostenible. Madrid: Ediciones MundiPrensa, 2000.

MCREYNOLDS, Samuel A. Guia para o iniciante em Sociologia do Meio Ambiente: definição, lista de jornais e bibliografia. Ambiente \& Sociedade, n. 5, July-Dec. 1999.

LAZZARETTI, Miguel Ângelo. A produção da ação coletiva no MST: relações de poder e subjetividade. João Pessoa: Universidade Federal da Paraíba: Universidade Federal de Campina Grande, 2007. 378 f. Tese (Doutorado em Sociologia) - Programa de PósGraduação Stricto Sensu em Sociologia, Universidade Federal da Paraíba: Universidade Federal de Campina Grande, João Pessoa - PB, 2007.

LEFF, Enrique. Agroecologia e saber ambiental. Agroecologia e Desenvolvimento Rural Sustentável, Porto Alegre, v.3, n.1, jan./mar. 2002.

LUDKE, M.; ANDRÉ, M. E. D. A. - Pesquisa em educação: abordagens qualitativas. São Paulo, E.P.U., 1986. 99p.

NIEDERLE; Paulo A.; ALMEIDA, Luciano de; VEZZANI, Fabiane Machado (Org.) Agroecologia: práticas, mercados e políticas para uma nova agricultura. Curitiba: Kairós, 2013.

OLIVEIRA, F. L. Manejo orgânico da cultura do repolho (Brassica oleracea var. capitata): adubação orgânica, adubação verde e consorciação. Rio de Janeiro: Universidade Federal Rural do Rio de Janeiro, 2001. 88f. Dissertação (Mestrado em Fitotecnia) - Programa de PósGraduação Stricto Sensu em Fitotecnia, Universidade Federal Rural do Rio de Janeiro, Seropédica - RJ, 2001.

PENTEADO, S. R. Introdução à agricultura orgânica: normas e técnicas de cultivo. Campinas: Grafimagem, 2000.

PETERSEN, P. Metamorfosis agroecológica: um ensayo sobre Agroecología Política. Baeza: UNIA, 2013.

ROMEIRO, A. R. Meio ambiente e dinâmica de inovações na agricultura, São Paulo: Annablume; FAPESP, 1998. 
SEVILLA GUZMÁN, Eduardo. A perspectiva sociológica em Agroecologia: uma sistematização de seus métodos e técnicas. Agroecologia e Desenvolvimento Rural Sustentável, Porto Alegre, v.3, n.1, jan./mar. 2002.

El despliegue de la Sociología Agraria hacia la Agroecología. Cuaderno Interdisciplinar de Desarrollo Sostenible - CUIDES. [Almería], n1.0, abril 2013.

La participación en la construcción histórica latinoamericana de la Agroecología y sus niveles de territorialidad. Política y Sociedad, v. 52, n.2, 2015, p. 351-370.

SEVILLA GUZMÁN, Eduardo; MIELGO, Antonio Alonso. Reflexões sociológicas sobre Agroecologia. Inguruak: Soziologia eta zientzia politikoaren euskal aldizkaria. Revista vasca de sociología y ciencia política, [País Vasco], n. 25, 1999, p.167-172.

SEVILLA GUZMAN, Eduardo; SOLER, Marta. Agroecología y soberanía alimentaria: alternativas a la globalización agroalimentaria. In: patrimonio cultural en la nueva ruralidad andaluza. PH Cuadernos. v.26. Sevilla: Consejería de Cultura/Junta de Andalucía, 2010.

SCOPINHO, R. A. Sobre cooperação e cooperativismo em assentamentos rurais. Psicologia \& Sociedade, 19, Edição Especial 1, 2007, p.84-94.

Em busca de "elos perdidos": projeto de assentamento e modos de identificação entre trabalhadores rurais assentados. Cadernos de Psicologia Social do Trabalho, v. 12, n. 2 , 2009. p. 257-270.

SCOPINHO, R. A.; MELO, T, G; GONÇALVES, J, C. Entre o Legal e o Real: Assentamentos Rurais do Tipo PDS na Macrorregião de Ribeirão Preto. Retratos de Assentamentos, UNIARA. Araraquara, v.19, n.1, 2016.

SOUZA, Andre Luiz de. Agricultura agroecológica como prática de sobrevivência e resistência no assentamento Ander Rodolfo Henrique. In: SIMPÓSIO SOBRE REFORMA AGRÁRIA E QUESTÕES RURAIS, VII, Araraquara, 29 a 01 julho 2016. (CD-ROM). ISBN: 97885-5510-011-6.

SIMMEL, G. Comment les formes sociales se maintiennent. L'Année sociologique, ano 1,1896-1897. p. 71-109,

WANDERLEY, M. de N. B. O mundo rural como um espaço de vida: reflexões sobre a propriedade da terra, agricultura familiar e ruralidade. Porto Alegre: UFRGS, 2009. 